\title{
Review
}

\section{Dysautonomia, A Heuristic Approach to a Revised Model for Etiology of Disease}

\section{Derrick Lonsdale}

24700 Center Ridge Road, Westlake, OH 44145, USA

\begin{abstract}
Dysautonomia refers to a disease where the autonomic nervous system is dysfunctional. This may be a central control mechanism, as in genetically determined familial dysautonomia (Riley-Day Syndrome), or peripherally in the distribution of the sympathetic and parasympathetic systems. There are multiple reports of a number of different diseases associated with dysautonomia. The etiology of this association has never been explained. There are also multiple publications on dysautonomia associated with specific non-caloric nutritional deficiencies. Beriberi is the prototype of autonomic dysfunction. It is the best known nutritional deficiency disease caused by an imbalance between ingested calories and the vitamins required for their oxidation, particularly thiamin. Long thought to be abolished in modern medical thinking, there are occasional isolated reports of the full-blown disease in developed Western cultures.

Apart from genetically and epigenetically determined disease, evidence is presented that marginal high calorie malnutrition, particularly with reference to simple carbohydrates, is responsible for widespread dysautonomia. The brain and heart are the organs that have a fast rate of oxidative metabolism and are affected early by any mechanism that reduces oxidative efficiency. It is hypothesized that this results in a chaotic state of the hypothalamic/autonomic/ endocrine axis. Due to the lack of adequate automatic controls, this may be responsible in some cases for breakdown of organ systems through long-standing energy deficiency, thus leading eventually to organic disease.
\end{abstract}

Keywords: Dysautonomia-Malnutrition-Oxidative dysfunction

\section{Introduction}

Dysautonomia is the term used for dysfunction in the autonomic nervous system. This automatic system is controlled by reflex mechanisms in the limbic system of the brain and brainstem. Dysfunction may also be engendered by faulty neurotransmission in the peripheral distribution of autonomic nerves. The sympathetic, or thoraco-lumbar outflow system, activates physical and mental action and its best known reflex is the fightor-flight. It is one of the many survival reflexes organized and initiated in the hypothalamus. The sympathetic

For reprints and all correspondence: Derrick Lonsdale, 24700 Center Ridge Road, Westlake Ohio 44145, USA. Tel: 440-835-0104;

Fax: 440-871-1404; E-mail: dlonsdale@pol.net system uses acetyl choline at the proximal ganglion and nerepinepthrine at the distal terminal ganglion.

The parasympathetic, or cranio-sacral outflow, opposes the actions of the sympathetic system. It uses acetyl choline at both the proximal and distal ganglia. Increased tone in one system is modulated by decreased tone in the other, an essential balance that results in a continuous adaptation to environment. The concept of homeostasis is more aptly seen as homeodynamics, a continuous reaction between environment and the adaptive status of the organism. Symptoms of dysautonomia are caused by inefficient, abnormal or unbalanced efferent signals distributed via the two systems. Examples of increased sympathetic tone are tachycardia, excessive sweating and 'panic attacks'. Increased parasympathetic tone may 
result, for example, in bradycardia, or increased intestinal peristalsis. Stress is defined in the ensuing text as the sensory input to the limbic system computer.

Sir Roger Bannister edited perhaps the most complete discussion of autonomic nervous system disease (1). In the various syndromes described in this book there is no reference to malnutrition in etiology. A well-known form of dysautonomia, albeit rare, is that originally described by Riley and associates and further described more completely by Riley (2), a genetically determined disease affecting Ashkenazic Jews. Riley and Moore (3) reported children, however, with a puzzling appearance of dysautonomia that did not completely conform to the symptomatology and physical signs considered to be necessary for this diagnosis.

The medical literature is replete with isolated reports of dysautonomia, associated with various disease entities. In none of these publications is the etiology of the dysautonomia made clear and it is always left as an isolated observation. Evidence is presented that loss of oxidative efficiency, particularly affecting the limbic brain and brainstem, is responsible for both the dysautonomia and possibly its associated organic disease. The underlying etiology can be genetic, epigenetic or due to imbalance between caloric and non-caloric nutrients as seen in beriberi, the prototype of functional dysautonomia.

\section{Review of Dysautonomia Literature}

Reports of dysautonomia appeared throughout the 20th century in literature that is now seldom studied. Coghlan et al. (4) noted the associations of dysautonomia with mitral valve prolapse and even suggested the possibility that this now common lesion might be a disorder of the patient's 'computer' (5). Mitral valve prolapse has been recognized in association with scoliosis (6), a phenomenon that occurs in familial dysautonomia (2). Renal sodium loss and bronchogenic carcinoma have been reported with dysautonomia (7). Adie was an early clinical investigator and many of the patients he described had asymmetry as part of the expression of the dysautonomia (8). Orthostatic hypotension, long known as a feature of dysautonomia, has been associated with amyloidosis (9), the Shy Drager syndrome (10) and Wernicke's disease (11). At least three publications reported forms of dysautonomia, one with recovery for which no explanation was offered (12-14). Rubin studied pupillary re-activity in psychotic adult patients and autistic children and found evidence of dysautonomia $(15,16)$. Abnormalities in circadian patterns have been published as implications for myocardial ischemia, a common cause of contemporary disease (17). Gutstein et al. (18) stated in 1978 that there was a great awareness of the role of behavioral responses in human ischemic heart disease. They reported electron microscopic evidence of early atherogenic changes in the aorta and coronary arteries in normally fed rats receiving electrical stimulation in the lateral hypothalamus. Dysautonomia was suggested as the underlying pathophysiology in four apparently healthy young adults with vague chest symptoms during the day, two of whom had infrequent nocturnal ambulatory syncope (19).

Both prolongation (20) and shortening (21) of the electrocardiac QT interval have been associated with autonomic dysfunction. Dysautonomia-related symptoms have been recorded in some cases of cyclic vomiting, a predominantly childhood condition (22). The authors suggested that an increased comorbidity with a distinct list of medical conditions in this syndrome may relate to a higher degree of mitochondrial dysfunction.

A French publication presented a case report of a woman with orthostatic hypotension, syncope and other signs of sympathetic dysfunction (23). The authors noted that chronic autonomic disorders may complicate a wide range of conditions that can be divided into secondary, due to specific diseases and primary, in which no cause has been determined. Hypervagal responses have been described as the underlying mechanism of dysautonomia rhinitis, an interesting association with the autonomic nervous system (24). Obstructive sleep apnea has been associated with abnormalities in stress tests of cardiovascular response in the autonomic nervous system (25). These authors reported low arterial oxygen that was proportional to the degree of abnormality. Thus, obstructive sleep apnea appears to operate by its secondary effect on the mechanisms involving automatic respiration. The obvious conclusion to be drawn is that the low oxygen saturation affected central control of the autonomic nervous system. Autonomic dysfunction in sleep apnea has also been associated with impaired glucose regulation (26).

Patients suffering from syncopal attacks were evaluated by studying their autonomic cardiovascular stimulation tests. The authors concluded that their syncope patients had dysautonomia that appeared as both a sympathetic and parasympathetic hypofunction (27). Neuralgiform headaches with conjunctival injection and tearing (SUNCT) and short-lasting unilateral neuralgiform headaches with cranial autonomic features (SUNA) were studied. A percentage of both these forms of headache were triggered by cutaneous tactile stimuli (28), suggesting an exaggerated or hyperactive central response.

The question raised here is whether there is a common etiology to tie so many reports of dysautonomia together. It is suggested that biochemical changes affect either the autonomic nervous system itself or its central control, leading to inefficient oxidative metabolism similar to the effects of hypoxia. 


\section{Oxidative Stress in Brain Disease}

Gibson and Zhang (29) reported oxidative stress in chronic brain disease involving disturbance of thiamin homeostasis. Kern and Jones (30) reviewed the evidence for oxidative stress in autism and Butterworth (31) compared the etiology of autism with that in Wernicke's encephalopathy (WKS). Both diseases involve loss of Purkinje cells and WKS has been reported in children (32). Purkinje cells are selectively vulnerable to oxidative insufficiency and the nature of tissue damage in thiamin deficiency resembles that observed following anoxic/ischemic insults $(30,31)$. Measurement of high energy phosphates in brains of symptomatic pyrithiamine-treated rats revealed decreases of ATP and phosphocreatine in the brainstems of affected animals (33).

A case report (34) revealed a possible complication of parenteral nutrition. When the patient died, autopsy showed the typical pathology of WKS, a brain lesion well known to be related to thiamin deficiency. This was in spite of the fact that $24 \mathrm{mg}$ of thiamin a day was provided in the intravenous fluid. It has to be concluded that the mechanism involved an imbalance between the concentration of administered glucose and the required redox potential. It might be compared with choking an internal combustion engine. This complication might also be explained by a failure to phosphorylate thiamin pyrophosphate (TPP) to synthesize thiamin triphosphate (TTP) (35). Although there is still insufficient knowledge about the role of TTP, it is known to be extremely important in energy metabolism in brain (36-40).

The oldest known nutritional deficiency disease is the ancient scourge of beriberi. It has long been known that the pathology associated with this is functional imbalance of the autonomic nervous system in the early stages of the disease and its ultimate destruction in the later stages (41). Indeed, the neurological symptoms and signs recorded many years ago in Japan were so diverse (Table 1) that they should be noted in our modern era where simple carbohydrates are consumed in enormous excess, particularly in Western cultures.

There is now general acceptance of the role of thiamin in the etiology of beriberi. But the disease must be understood in its obvious association with the biochemistry of glucose in energy metabolism. One of the important observations made in studying patients with beriberi was that arterial oxygen saturation is relatively low in the disease when venous oxygen concentration is relatively high (41, Table 1), the same phenomenon as was reported in sleep apnea (25) and also reported to be related to glucose dysregulation (26).

It has long been known that increasing the ingestion of simple carbohydrate in the diet automatically increases thiamin requirements. Lonsdale and associates provided evidence that the enormous consumption of sugar in
Table 1. Neurological symptoms and signs of beriberi (41)

General nutritional state appears to be good: e.g. seen in robust workers

Edema

Diencephalic dysfunctional control of autonomic nervous system

Cardiac palpitation on mental or physical exertion

Increased cardiac output

EKG changes; abnormal T waves; prolonged QT interval

Dicrotic pulse

Low diastolic pressure, may reach zero; normal or high systolic blood pressure

Audible femoral pulse, particularly in children

Low arterial, high venous oxygen concentration

Labile vasomotor function; abnormal response to adrenalin and atropine

Vagotonia/Sympathicotonia

Increased basal metabolic rate

Sequential sensory disturbances, including parasthesiae

Proprioceptive perception decreased after superficial sensory changes

America represents high calorie malnutrition (42-45). One of these publications (45) discussed the role of thiamin deficiency in lower brain dysfunction that could have serious effects in automatic control mechanisms of the autonomic nervous system. This included a case report of a woman whose thiamin deficiency produced symptoms that were very suggestive of imitating high altitude sickness, caused in some people sensitive to the rarefied oxygen concentration. Oxygen-chemosensitive sites are distributed throughout the brain stem from the thalamus to the medulla and may form an oxygenchemosensitive network (46).

\section{Dysautonomia and Nutritional Deficiency}

The recent scientific literature involving the autonomic nervous system is represented in relation to its biochemical etiology and the relation with nutrition. Autonomic dysfunction has been studied in malnourished children (47). The sympathetic nervous system plays an important role in the regulation of adipose tissue lipolysis. Elevated baseline and exercise-induced sympathetic nervous activity and exercise-induced lipolysis in adipose tissue were reported in anorexia nervosa (48). Whether this is the primary etiology or secondary to the ensuing malnutrition is not clear.

Autonomic dysfunction has been reported in vitamin B12 deficiency $(49,50)$. Evidence was provided that sympathetic nervous activity in vitamin E-deficient rats was greater than in control animals (51). Chronic exposure to moderate and severe hypoxia increases the activity of the sympathetic nervous system and adrenal medulla in rats (52) and thiamin deficiency induces an early functionally significant central muscarinic cholinergic lesion in rat studies (53). Another rat study suggested that the sympathetic nervous system in spleen and heart were stimulated by vitamin A deficiency (54). Magnesium deficiency has been shown to play a role 
in the pathogenesis of mitral valve prolapse (55), already mentioned in this review as being associated with dysautonomia $(4,5)$. Autonomic system excitability (56) and autonomic circulatory regulation in rats (57) have been associated with magnesium deficiency. The biological basis of antisocial and aggressive behavior in children was reviewed with a focus on low autonomic functioning, pre-frontal deficits and early health factors that include malnutrition in pregnancy (58). In heavy drinkers with evidence of autonomic neuropathy revealed by various tests, erectile dysfunction appeared to be the sole symptom, involving loss of parasympathetic function. The authors stated that none of the studied patients showed signs of caloric/protein malnutrition but vitamin/ mineral deficiency was not recorded (59).

Reversible autonomic dysfunction associated with high calorie malnutrition has been reported (60). The clinical presentation can be asymmetric (61). Sweating, tachycardia, dermographia, both wide and narrow unstable pulse pressure, attention deficit and other dysautonomic symptoms in children have been published (62). These symptoms have been shown to respond to dietary instruction, with particular reference to removal of sugar in all its commercial forms together with dietary supplements that always include thiamin and magnesium.

\section{Dysautonomia in Autism and Sudden Infant Death Syndrome}

Simon (63) suggested a metabolic similarity in WKS and autism. It was pointed out that thiamin deficiency, by disabling the aerobic pathway for glucose metabolism, is equivalent to oxygen deprivation. An acute episode of asphyxia brought about by different means, affects the same brainstem nuclei.

Dysautonomia has now been shown to be relevant in autism (64). These investigators reported a skewed representation of male subjects, an observation that is well known in this disease. Sudden infant death syndrome (SIDS) has the same representation of male dominance. Brainstem dysfunction has been reported in $\operatorname{SIDS}(65,66)$. It has been suggested that infants succumbing to this death require the combination of genetic predisposition, one or more stress factors and defective oxidative metabolism that might be related to nutrient deficiency (67). These observations are similar to the combination of factors reported in autism (30). Thiamin supplementation has been reported to be beneficial in autism (68), in SIDS (69-73) and thiamin triphosphate deficiency was reported in the phrenic nerve of SIDS victims (74).Clinical improvement in autistic spectrum disorders has been reported from treatment with secretin (75). The investigators suggested that the action of secretin was through brain stimulation since there are known receptors for this
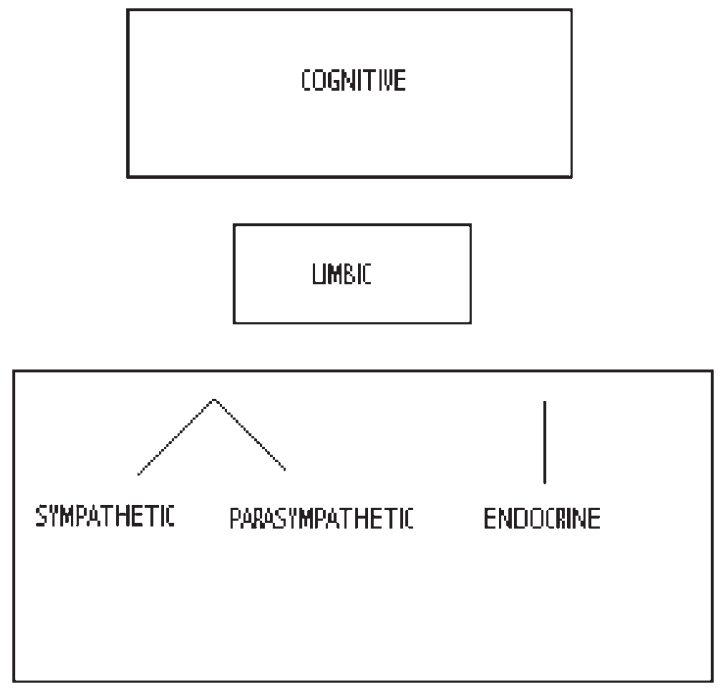

Figure 1. A revised model for disease. Diagrammatic representation of the brain-body communication system. The limbic system is presented as a computer that enables continuous energy-dependent adaptation to environmental stress.

hormone in the hippocampus. A clinical study reported varying degrees of improvement in behavior and/or bowel function using a single injection of secretin (76). One 7-year-old boy, included in this study, had great improvement in behavior noted by his parents. They also reported an observation that clearly suggested improved autonomic function. Before the single injection of the hormone, this child had pupils that were noted to be fixed and dilated, not even responding to sunlight. Immediately following the injection his pupils began to respond normally to light.

\section{The Use of Boolean Algebra in Representing the Interrelationship of Variables}

Figure 1 represents a strictly functional differentiation. There is no attempt to suggest an anatomical configuration in separating the cognitive from the limbic systems.

Figure 2 presents three necessary variables that overlap each other. Genetics, represented by the first circle, always needs to be factored in, but in most cases the physician has no knowledge of his patient's genome. Even a family history does not provide clues since the underlying biochemical mechanism of a given inherited disease is often unknown. There are obvious exceptions such as phenylketonuria and other inborn errors of metabolism where specialized dietary therapy is the only recourse, but even those have variants. It is suggested that the genome contains genetic traits that may constitute unknown weaknesses such as enzymatic polymorphisms. Genetic predisposition is usually an unknown that cannot be blamed for the onset of disease on its 


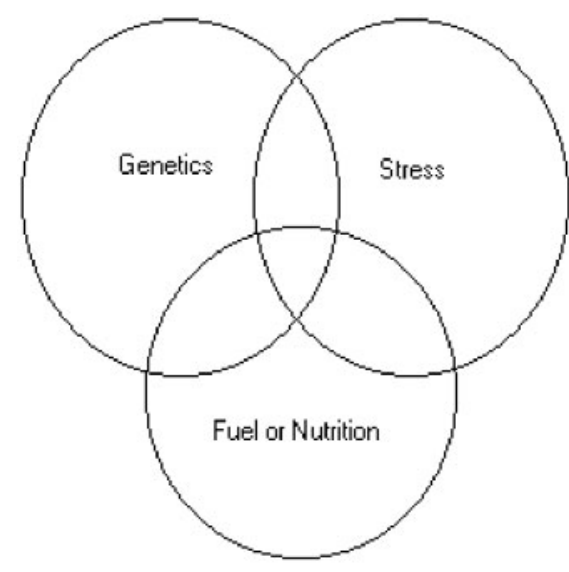

Figure 2. The three circles of health.

own unless it is a flagrant Mendelian abnormality, leading on its own to loss of function.

The first reported case of thiamin-dependent pyruvic dehydrogenase deficiency (78) was a child whose episodes of cerebellar ataxia were initiated by infection, inoculation or head injury. Intermittent branched chain ketoaciduria is initiated by infection (79). The functions of the genome are now known to be influenced by environmental factors, diet and life style. This has given rise to the newest science of epigenetics.

The second interlocking circle is labeled 'stress' the inevitable result of being alive in a hostile environment. It can obviously be divided into its mental input, often thought of as the only form of stress encountered by humans and its physical input, such as injury, infection or inoculation. Both mental and physical stress response is energy consuming. Adaptive mechanisms are automatically put in effect through the autonomic nervous and endocrine systems, controlled by the limbic brain. The cognitive brain is aware but may fail to suppress the limbic action, a phenomenon that gives rise to lack of self control. The best-known reflex is 'fight-or-flight' and so-called 'panic attacks' are obviously fragmented examples of this reflex, extremely common today in my experience. The limbic 'computer' is equipped with a host of survival reflexes involving thirst, hunger and sexual drive. Each is designed for survival of the species (e.g. sexual drive) or the individual (thirst, hunger). The stress, if not in itself overwhelming such as severe trauma, is monitored and data processed by the limbic 'computer' and the necessary adaptive machinery is put into action. Such obvious ones are how the brain adapts to mental insult emotionally and how it initiates adaptation to physical factors such as environmental temperature, or change in barometric pressure. Circadian rhythm adapts us to the day/night cycle and seasonal adaptive disease is an obvious example of failed adaptation. If cellular energy is deficient the necessary adaptive response is inappropriate. As in beriberi, however, these reflex reactions, mediated through the hypothalamic/endocrine/autonomic axis are increased in the early stages of marginal high calorie malnutrition.

Observation of many patients in our clinic has led to the conclusion that high calorie malnutrition results in hypersensitivity of the limbic system. The reflex mechanisms initiated by sensory input from environmental influences become exaggerated. The hypothalamic/ endocrine/autonomic axis and limbic system emotional reactions become activated much too easily by virtually any form of stress input. When the empty calories are removed from the diet, particularly simple carbohydrates, the symptoms disappear and the adaptive reflexes return to normal. Before treatment, such individuals become easily angered and are emotionally labile. This has strongly suggested that this form of malnutrition might be responsible for some of the otherwise inexplicable juvenile crime so common today $(80,81)$. Mild insults that would normally be either ignored or initiate normal anger response become exaggerated in the processing of hostile information.

The third circle is labeled 'fuel' or 'nutrition'. The design of an automobile might be likened to the genome in humans. Its fuel requirements are part of the engine design. The human body is designed with the need for a complex of organic nutrients. If these nutrients are replaced with empty calories we incur risk of inefficient metabolism and this will affect the most oxygen demanding tissues. It is, therefore, not surprising that beriberi is an example of a relatively high calorie nutritional deficiency disease that causes failure is the most oxygen demanding organs, brain, nervous system and heart. Thiamin stands at the gate of the citric acid cycle, a key factor is aerobic metabolism, but this vitamin is only one of the principles necessary. Its place in that function, however, can be used as a model for what happens when the result in inefficient energy synthesis.

Evidence offered in this manuscript indicates that a victim of high caloric malnutrition becomes poorly adapted to the constant daily input of environmental stressors, resulting in autonomic/endocrine dysregulation. A very old experiment in human volunteers led to multisymptom functional changes that ensued when the subjects were exposed to a thiamin-deficient diet (82). It is virtually certain that the present existing model for disease would label the symptomatology as 'nervous, neurotic or psychosomatic'. In the later stages, the result of increasingly inefficient oxidative metabolism, the normal adaptive signaling processes break down and degenerative organ disease may well be a result. As the immune response breaks down there is more susceptibility to overwhelming infection. Opportunist organisms may invade where aerobic metabolism is degraded. Microorganisms are stressors and normally 
initiate defense mechanisms mediated by the 'computer'. The gradual decay in metabolic function may lead to the variable effects associated with disease, aging and eventual death.

\section{Conclusions and Hypothesis}

Evidence has been produced to indicate that various forms of mild to moderate vitamin deficiencies result in functional changes in the autonomic nervous system. This is clearly shown by a study of the clinical effects seen in beriberi (41). It is hypothesized that the predictable loss of efficiency in oxidative metabolism is the key to understanding the association of dysautonomia with many different diseases.

It is suggested that a gradual increase in oxidative dysfunction also gives rise to changes in organs, causing subsequent organic disease in some cases. The ample evidence of dysautonomia with various nutrient deficiencies, referenced in this article, suggests strongly that the state of redox potential in the high oxygen demand automatic centers of the brainstem and limbic system is impaired.

This would explain why dysautonomia is reported in so many isolated case reports where the published association appears to be little more than an interesting observation. Evidence is presented here that one method of inducing this is by high caloric malnutrition involving excessive ingestion of empty calories, a potent factor in functional disease that is being overlooked, particularly in children. When diet histories are considered carefully it is sometimes obvious that there is more attention to the content of meals rather than the consumption of ad lib snacks between meals. In one boy seen in our clinic the consumption of cola amounted to about 2 gallons a week. Often children like this are being given vitamin supplements under the false impression that this would prevent any consideration of nutritional deficiency. This approach does not encourage the dietary self responsibility involved in preserving individual health. Evidence has been presented to indicate that a genetically or epigenetically determined weakness in the genome is responsible for intermittent disease in some inborn errors of metabolism, creating susceptibility to environmental stress factors, such as infection. Polymorphisms, common in the population, appear to provide a genetic risk to many children in the increasingly severe industrial pollution that we face in the modern world (30).

Chronic fatigue syndrome, considered to be related to mitochondrial inefficiency, SIDS and autistic spectrum disorder (ASD) (83) are presented here as typical examples of genetic or epigenetic risk, the stress factors being one or more of several possibilities including heavy metal toxicity, antibiotic abuse, infection with micro-organisms, industrial and possibly electromagnetic pollution and various forms of mental pressures imposed by civilization. To meet the imposed stress factor requires an adaptive response that requires appropriate nutrition and lifestyle to provide the necessary energy. Various successful therapeutic measures such as acupuncture suggest that electrical or electromagnetic energy is used for intracellular communication. Whether this is generated from biochemical action or not is unknown at present. An individual unable to meet the required energy demand might be seen as maladapted to the environment.

The tongue is a sensory organ that provides taste input to the receptor cells in brain. Since this consists of stimuli from sweet, sour, bitter, salt, astringent and metallic, all organic foods provide permutations and combinations of sensory stimulation that the brain interprets as flavor. Thus, the sensual pleasure derived from sugar (or any other sweetener) alone is suggested as an explanation of its addictive nature. Many polysymptomatic patients are similarly salt cravers. Removing them completely results in symptomatic improvement in many of the patients treated in our clinic. It is suggested that high caloric malnutrition, particularly in the form of simple carbohydrates, is a common cause of defective autonomic control mechanisms in the lower brain that can be likened to the early stages of classic beriberi.

\section{References}

1. Bannister R. Autonomic Failure. Oxford, Walton Street: Oxford University Press, OX2 6DP, 1984, 1-666.

2. Riley CM. Familial dysautonomia. Adv Pediatr 1957;9:157-90.

3. Riley CM, Moore RH. Familial dysautonomia differentiated from related disorders. Pediat 1966;37:435-46.

4. Coghlan HC, Phares P, Cowley M, Copley D, James TN. Dysautonomia in mitral valve prolapse. Am J Med 1979;67:236-44.

5. Coghlan HC. Mitral Valve Prolapse: Is It a Disorder of the Patient's 'Computer'? American Heart Association's Eighth Science Writers Forum. Tucson, Arizona. January 1981.

6. Hirschfeld SS, Nash CL, Nussbaum E, Brower EM. Incidence of mitral valve prolapse in adolescent scolisis and chronic hypokyphosis. Pediat 1982;70:4451-54.

7. Ivy HK. Renal sodium loss and bronchogenic carcinoma: associated autonomic neuropathy. Arch Int Med 1961;108:47-55.

8. Adie WJ. Tonic pupils and absent tendon reflexes: a benign disorder sui generis; its complete and incomplete forms. Brain 1932;55:988-1113.

9. Kyle RA, Kattke BA, Schinger A. Orthostatic hypotension as a clue to primary systemic amyloidosis. Circulation 1966;34:883-8.

10. Shy G, Drager GA. A neurological syndrome associated with orthostatic hypotension. Arch Neurol 1960;2:511-27.

11. Birchfield RI. Postural hypotension in Wernicke's disease. Am J Med 1964;36:404-14.

12. Young RR, Asbury AK, Adams RD, Corbett JL. Pure pandysautonomia with recovery. Trans Am Neurol Assoc 1969;94:355-7.

13. Thomashefsky AJ, Horwitz SJ, Feingold MH. Acute autonomic neuropathy. Neurol 1972;22:251-5.

14. Appenzeller O, Kornfeld M. Acute pandysautonomia. Arch Neurol 1973;29:334-9.

15. Rubin LS. Pupillary reactivity as a measure of psychotic behavior. J Nerv MEnt Dis 1960;130:386-400.

16. Rubin LS. Patterns of pupillary dilatation and constriction in psychotic adults and autistic children. $J$ Nerv Ment Dis 1961;133:130-42.

17. Pepine CJ. Circadian variations in myocardial ischemia: Implications for management. JAMA 1991;265:386-90. 
18. Gutstein WH, Harrison J, Parl F, Kiu G, Avitable M. Neural factors contribute to atherogenesis. Science 1978;199:449-51.

19. Guilleminault C, Pool P, Motta J, Gillis AM. Sinus arrest during REM sleep in young adults. $N$ Engl $J$ Med 1894:311:1006-10.

20. Schwartz APJ, Apriori SG, Dumaine R, Napolitano C, Antzelevitch $\mathrm{C}$, et al. A molecular link between the sudden infant death syndrome and the long-QT syndrome. $N$ Engl $J$ Med 2000;343:262-7.

21. Naschitz J, Fields M, Isseroff H, Sharif D, Sabo E, Rosner I. Shortened QT interval: a distinctive feature of the dysautonomia of chronic fatigue syndrome. J Electrocardiol 2006;39:389-94.

22. Bates RG, Powers AL, Adams K. Cyclic vomiting syndrome plus. $J$ Child Neurol 2006;21:182-8.

23. Laksini N, Azulay JP, Uzenot D, Pouget J. Idiopathic chronic dysautonomia: when should the diagnosis be made? Rev Neurol (Paris) 2006;162:869-71.

24. Eisheikh MN, Badran HM. Dysautonomia rhinitis: Associated otolaryngologic manifestations and characterization based on autonomic function tests. Acta Laryngol 2006;26:1206-12.

25. Veale D, Pepin JL, Wuyam B, Levy PA. Abnormal autonomic stress responses in obstructive sleep apnoea are reversed by nasal continuous positive airway pressure. Eur Resp J 1996;9:2122-6.

26. Peltier AC, Consens FB, Sheikh K, Wang L, Song Y, Russell JW. Autonomic dysfunction in obstructive sleep apnea is associated with impaired glucose regulation. Sleep Med 2007;PMID 17236808.

27. Martin-Gonzalez RS, Salas-Tomas MC, Monge-Argiles JA. Evaluation of autonomic cardiovascular functioning in patients with syncope. Rev Neurol (Spanish) 2006:43:461-5.

28. Cohen AS, Matharu MS, Goadsby PJ. Short-lasting unilateral neuralgiform headache attack with conjunctival injection and tearing (SUNCT) or cranial autonomic features (SUNA)- a prospective clinical study of SUNCT and SUNA. Brain 2006;129:2746-60.

29. Gibson GE, Zhang H. Interactions of oxidative stress with thiamin homeostasis promote neurodegeneration. Neurochem Int 2002; $40: 493-504$

30. Kern JK, Jones AM. Evidence of toxicity, oxidative stress and neuronal insult in autism. $J$ Toxicol Environ Health, Part $B$ 2006;9:485-99.

31. Butterworth RF. Pathology of cerebellar dysfunction in the Wernicke-Korsaskoff syndrome. Can J Neurol Sci 1993;20:5123-26.

32. Vasconcelos MM, Silvak P, Vidal G, Silva AF, Dominques RC, Berditevschky CR. Early diagnosis of pediatric Wernicke's encephalopathy. Pediatr Neurol 1990;20:289-94. PMID 10328278.

33. Aikawa H, Watanabe IS, Furuse T, et al. Low energy levels in thiamine-deficient encephalopathy. $J$ Neuropathol Exp Neurol 1984:43:276-87.

34. Lonsdale D. Wernicke's encephalopathy and hyperalimentation. JAMA 1978;239:1133.

35. Cooper JR, Pincus JH. The role of thiamine in nervous tissue. Neurochem Res 1979;4:223-39.

36. Iwata H, Yabushita Y, Doi T, Matsuda T. Synthesis of thiamine triphosphate in rat brain in vivo. Neurochem Res 1985;10:779-87.

37. Bettendorf L, Michel-Cahay C, Grandfils C, De Rycker C, Schoffeniels E. Thiamine triphosphate and membrane-associated thiamine phosphatases in the electric organ of Electophorus Electricus. J Neurochem 1987;49:495-502.

38. Bettendorf L, Hennuy B, DeCherek A, Wins P. Chloride permeability of rat brain vesicles correlates with thiamine triphosphate content. Brain Res 1994;652:157-60.

39. Bettendorf L, Kolb HA, Schoffeniels E. Thiamine triphosphate activates anion channels of large conductance in neuroblastoma cells. J Membr Biol 1993;136:281-88.

40. Makarchikov AE, Lakaye B, Gulyai IE, Czerniecki J, Courmans B, Wins $\mathrm{P}$, et al. Thiamine triphosphatase and thiamine triphosphatase activities:from bacteria to mammals. Cell Mol Life Sci 2003:60:1477-88.

41. Inouye K, Katsura E. Clinical signs and metabolism of beriberi patients. In: Shimazono N, Katsura E (eds). Beriberi and Thiamine. Tokyo: Igaku Shoin Ltd, 1965, 29-63.

42. Lonsdale D, Shamberger RJ. Red cell transketolase as an indicator of nutritional deficiency. Am J Clin Nutr 1980;33:205-11.
43. Lonsdale D. Red cell transketolase studies in a private practice specializing in nutritional correction. $J$ Am Coll Nutr 1988;7:61-7.

44. Lonsdale D. A review of the biochemistry, metabolism and clinical benefits of thiamin(e) and its derivatives. Evid Based Complement Alternat Med 2006;3:49-59.

45. Lonsdale D. Three case reports to illustrate clinical applications in the use of erythrocyte transketolase. Evid Based Complement Altern Med 2007;4(2):247-50.

46. Neubauer JA, Sunderram J. Oxygen-sensing neurons in the central nervous system. J Appl Physiol 2004;96:367-74.

47. Bedi M, Bubbar R, Chakrabarty AS, Sachdev HP. Comparative study of autonomic nervous activity in malnourished children in India. Ann Trop Paediatr 1999;19:185-9.

48. Bartak V, Vybiral S, Papezova H, Dostalova I, Pacak K, Nedvidkova J. Basal and exercise-induced sympathetic nervous activity and lipolysis in adipose tissue of patients with anorexia nervosa. Eur J Clin Invest 2004;34:371-7.

49. Beitzke M, Pfister P, Fortin J, Skrabal F. Autonomic dysfunction and hemodynamics in vitamin B12 deficiency. Auton Neurosci 2002;97:45-54

50. Moore A, Ryan J, Watts M, Pillay I, Clinch D, Lyons D Orthostatic intolerance in older patients with vitamin B12 deficiency before and after vitamin B12 replacement. Clin Auton Res 2004; 14:67-71.

51. Nakashimna Y, Esashi T. Age-related changes in sympathetic nervous activity of rats receiving viamin E-deficient diet. Nutr Sci Vitaminol 1986;32:569-79.

52. Johnson TS, Young JB, Landsberg L. Sympathoadrenal responses to acute and chronic hypoxia in the rat. $J$ Clin Invest 1983;71:1263-72.

53. Barclay LL, Gibson GE, Blass JP. Impairment of behavior and acetylcholine metabolism in thiamine deficiency. J Pharmacol Exp Ther 1981;217:537-43.

54. Nakano K, Mizutani R. Increased sympathetic nervous system activity in rat spleen and heart following vitamin A depletion. Nutr Sci Vitaminol 1984;30:163-70.

55. Galland LD, Baker SM, McLellan RK. Magnesium deficiency in the pathogenesis of mitral valve prolapse. Magnesium 1986:5:1655-74.

56. Durlach J, Bac P, Durlach V, Bara M, Guiet-Bara A. Neurotic, neuromuscular and autonomic nervous form of magnesium imbalance. Magnes Res 1997;10:169-95.

57. Murasato Y, Harada Y, Ikeda M Nakashima Y Hayashida Y Effect of magnesium deficiency on autonomic circulatory regulation in conscious rats. Hypertension 1999;34:247-52.

58. Raine A. Annotation: the role of prefrontal deficits, slow autonomic arousal, and early health factors in the development of antisocial and aggressive behavior in children. $J$ Child Psychol Psychiatry 2002;43:417-34.

59. Ravaglia S, Marchioni E, Costa A, Maurelli M, Moglia A. Erectile dysfunction as a sentinel symptom of cardiovascular autonomic neuropathy in heavy drinkers. J Periph Nerv Syst 2004;9:209-14

60. Lonsdale D. The syndrome of functional dysautonomia Med Hypoth 1981;7:495-502.

61. Lonsdale D. Asymmetric functional dysautonomia. J Nutr Med 1990;1:59-61.

62. Lonsdale D. Nutritional therapy in children with functional disorders of activity, behavior, attention and learning. Clin Pract Altern Med 2001;2:196-203.

63. Simon N. Infantile autism and Wernicke's encephalopathy. Med Hypoth 1990;32:169-72.

64. Ming X, Julu POO, Brimacombe M, Connor S, Daniels ML. Reduced cardiac parasympathetic activity in children with autism. Brain Dev-Jpn 2005;27:509-16.

65. Orlowski JP, Nodar RH, Lonsdale D. Abnormal brainstem auditory evoked potentials in infants with threatened sudden infant death syndrome. Cleve Clin Quart 1979;46:77-81.

66. Nodar RH, Lonsdale D, Orlowski JP. Abnormal brainstem potentials in infants with threatened sudden infant death syndrome. Otolaryngol Head Neck Surg 1980;88:619-21. 
67. Lonsdale D. Sudden infant death syndrome requires genetic predisposition, some form of stress and marginal malnutrition. Med Hypoth 2001;53:382-6.

68. Lonsdale D, Shamberger RJ, Audhya T. Treatment of autistic spectrum children with thiamine tetrahydrofurfuryl disulfide: a pilot study. Neuroendocrinol Lett 2002;23:303-8.

69. Lonsdale D, Mercer RD. Primary hypoventilation syndrome. Lancet 1972;ii:487 (Letter).

70. Lonsdale D. Treatment of threatened SIDS with megadose thiamine hydrochloride. Pediat Res 1977;11:379 (Abstract)

71. Lonsale D, Nodar RH, Orlowski JP. The effects of thiamine on abnormal brainstem auditory evoked potentials. Cleve Clin Quart 1979;46:83-8.

72. Lonsdale D, Nodar RH, Orlowski JP. Brainstem dysfunction in infants responsive to thiamine disulfide: Preliminary studies in four patients. Clin EEG 1982;13:82-8.

73. Lonsdale D. Thiamine deficiency and sudden deaths. Lancet 1990;ii:376.

74. Barker JN, Jordan F, Hillman DE, Barlow O. Phrenic thiamine and neuropathy in sudden death Infants. In: Sable HZ, Gubler CJ (eds). Thiamin: Twenty Hears of Progress. Ann NY: Acad Scim 1982;378:449-52.

75. Horvath K, Stefanatos G, Sokolski KN, Wachtel R, Nabors L, Tilden JT. Improved social and language skills after secretin administration in patients with autistic spectrum disorders. $J$ Assoc Acad Minor Phys 1998:9:9-15.
76. Lonsdale D, Shamberger RJ. A clinical study of secretin in autism and pervasive developmental delay. J Nutr Enviorn Med 2000;10:271-80.

77. Lonsdale D. The three circles of health. In: Why I Left Orthodox Medicine. Charlottesville: Hampton Roads Publishing Company, Inc, 1994, 189-207.

78. Lonsdale D, Faulkner WR, Price JW, Smeby RR. Intermittent cerebellar ataxia associated with hyperpyruvic acidemia, hyperalaninemia and hyperalaninuria. Pediatr 1969;43:1025-34.

79. Dancis J, Hutzler J, Rokkones T. Intermittent branched-chain ketonuria. Variant of maple-syrup-urine disease. $N$ Engl $J$ Med 1967;276:84-9.

80. Lonsdale D. Criminal behavior and nutrition. $J$ Adv Med 1992;5:115-23.

81. Lonsdale D. Criminal violence: a hypothetical explanation of its relationship with high calorie malnutrition. $J$ Adv Med 1994; 7:171-80.

82. Williams RD, Mason HL, Marschelle HP, Russell MW. Induced thiamine (vitamin B1) deficiency in man. Arch Int Med 1943;71:38-53.

83. Pieczenik SR, Neustadt J. Mitochondrial dysfunction and molecular pathways of disease. Exp Mol Pathol 2007;PMID 17239370.

Received March 5, 2007; accepted May 2, 2007 


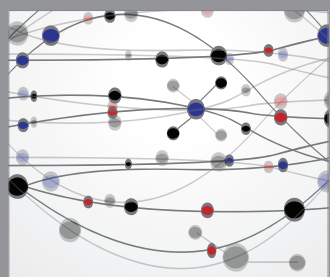

The Scientific World Journal
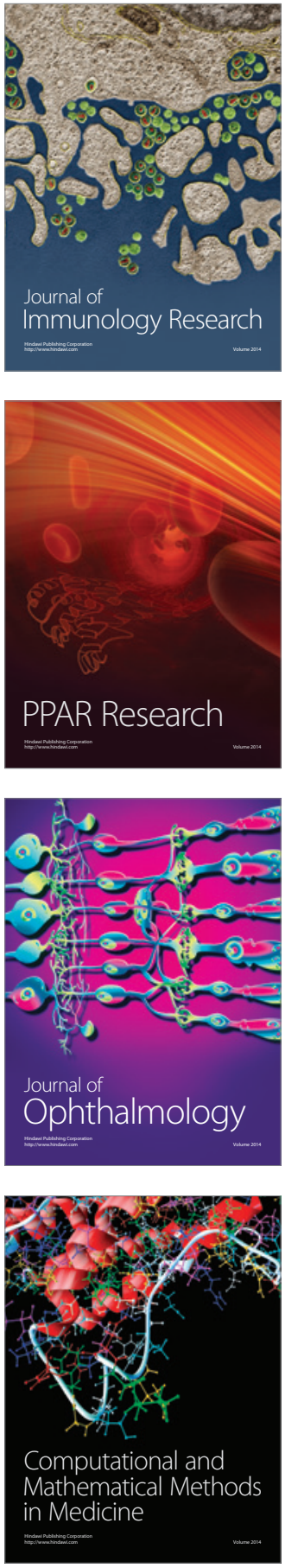

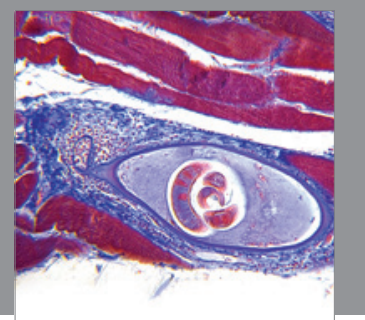

Gastroenterology

Research and Practice
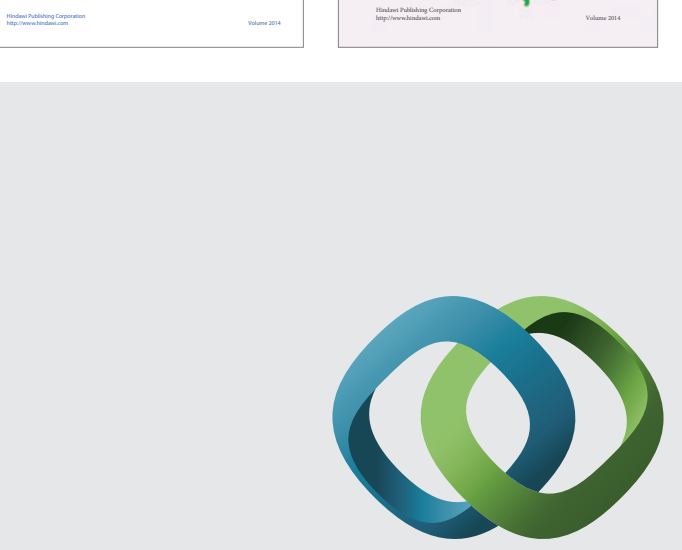

\section{Hindawi}

Submit your manuscripts at

http://www.hindawi.com
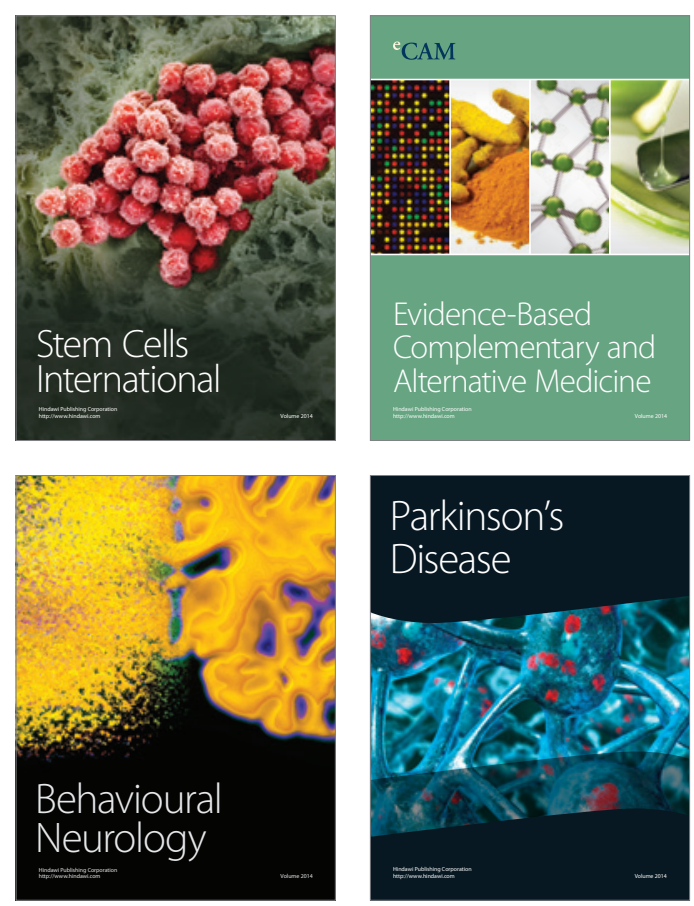

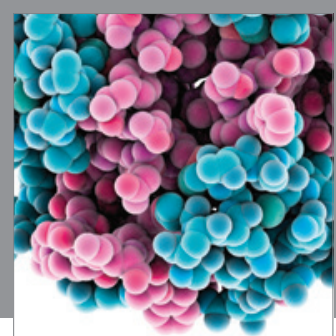

Journal of
Diabetes Research

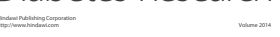

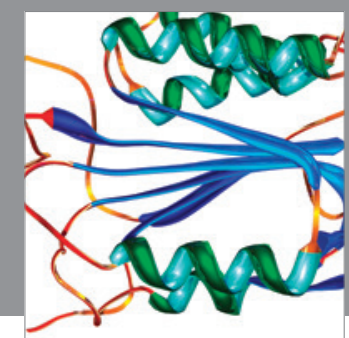

Disease Markers
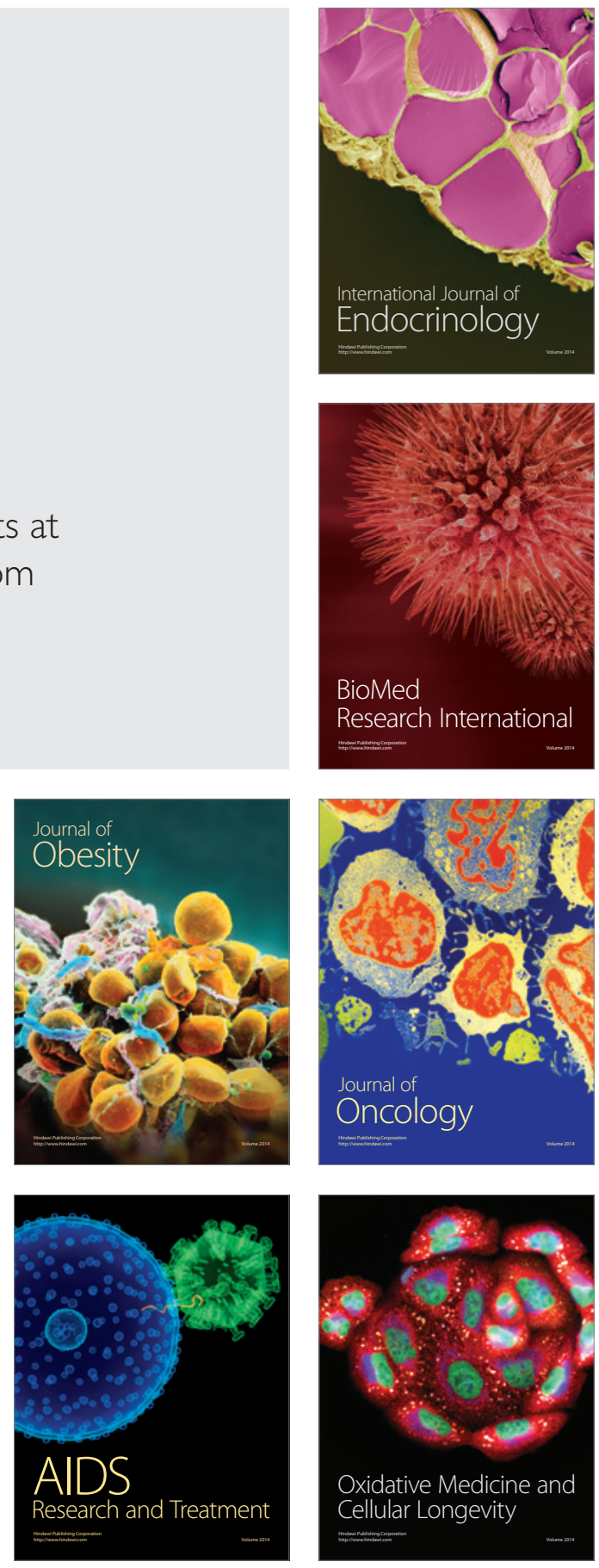